\title{
Epidemiological profile of leprosy reactions in a referral center in Campinas (SP), Brazil, 2010-2015*
}

\author{
Letícia Ambrosano ${ }^{1}$ \\ Elaine Cristina Faria Abrahão Machado ${ }^{2}$
}

\author{
Marcel Alex Soares dos Santos ${ }^{2}$ \\ Elisangela Samartin Pegas $3,4,5$
}

DOI: http://dx.doi.org/10.1590/abd1806-4841.20187260

Abstract: Leprosy patients can present reactions during the course of the disease. There are no official data on these reactions in Brazil. We aimed to describe the epidemiological characteristics of patients with such reactions, analyzing information from patient records at a referral center in Campinas (SP), from 2010 to 2015.

Keywords: Leprosy; Leprosy, Borderline; Leprosy, lepromatous; Leprosy, multibacillary; Leprosy, paucibacillary; Leprosy, tuberculoid

Leprosy patients can present complications over the course of the disease and may experience leprosy reactions, an acute hypersensitivity reaction to Mycobacterium leprae antigens resulting from the immune process, accompanied by an increase in proinflammatory cytokines and immune complexes. ${ }^{1-10}$

Such reactions can occur before, or more often during or after treatment, and their characteristics are influenced by the clinical form of the disease. ${ }^{3}$

Type 1 reactions usually occur in more reactive patients and generally reflect improvement in the defense to M. leprae. The specific lesions tend to increase in size and number, acquiring inflammatory characteristics, commonly involving nerves. ${ }^{4}$

Type 2 reactions are caused by compensatory exacerbation of humoral immunity in Virchowian patients, normally accompanied by systemic injury ${ }^{3,6}$ Clinical presentation shows generalized erythema nodosum or polymorphous erythema, usually preceded by polyarthralgia and fever. ${ }^{3-6}$

Brazil's official leprosy information system does not allow obtaining data on leprosy reactions, since they are not infectious-contagious phenomena and are not recorded as leprosy under the WHO guidelines. ${ }^{1,7}$ Data on frequency, severity, and individual patient characteristics can only be obtained from scientific publications.
Leprosy reactions often influence leprosy retreatment and are responsible for treatment dropout and physical disabilities. They are immune phenomena, often poorly understood, that express a peculiar clinical condition and require the dermatologist's specialized care. ${ }^{1-10}$

We conducted a cross-sectional observational study with the aim of describing epidemiological features of patients with leprosy reactions that had been reported as leprosy cases and were under treatment at a referral center in Campinas, São Paulo, Brazil. Data were analyzed from the medical records of patients reported as leprosy cases in this referral center from 2010 to 2015 and that had presented type 1 or type 2 reactions $(n=41)$.

The variables were gender, age bracket, clinical forms, operational classification, type of leprosy reaction, time of onset in relation to the leprosy treatment period, and form of treatment. Statistical analysis used simple frequencies. The study was conducted according to the ethical standards set out in the Declaration of Helsinki and was approved by the university hospital's institutional review board.

Ninety-one leprosy cases were diagnosed and notified during the study period at the outpatient referral clinic. Of these, 41 cases $(45.05 \%)$ presented some type of leprosy reaction. As for the

Received 01 May 2017.

Accepted 25 August 2017.

* Work conducted at the Dermatology Outpatient Clinic, Hospital e Maternidade Celso Pierro, Pontifícia Universidade Católica de Campinas (PUC-Campinas), Campinas (SP), Brazil.

Financial support: None.

Conflict of interest: None.

Dermatology Outpatient Clinic, Hospital da Pontifícia Universidade Católica de Campinas (PUC-Campinas), Campinas (SP), Brazil.

Graduate Studies Program in Health Sciences, Pontifícia Universidade Católica de Campinas (PUC-Campinas), Campinas (SP), Brazil.

Leprosy Clinic in the Dermatology Residency, Pontifícia Universidade Católica de Campinas (PUC-Campinas), Campinas (SP), Brazil.

Phototherapy Clinic in the Dermatology Residency, Pontifícia Universidade Católica de Campinas (PUC-Campinas), Campinas (SP), Brazil.

Bullous Diseases Clinic in the Dermatology Residency, Pontifícia Universidade Católica de Campinas (PUC-Campinas), Campinas (SP), Brazil.

MAILING ADDRESS:

Letícia Ambrosano

E-mail: leambrosano@hotmail.com

C2018 by Anais Brasileiros de Dermatologia 


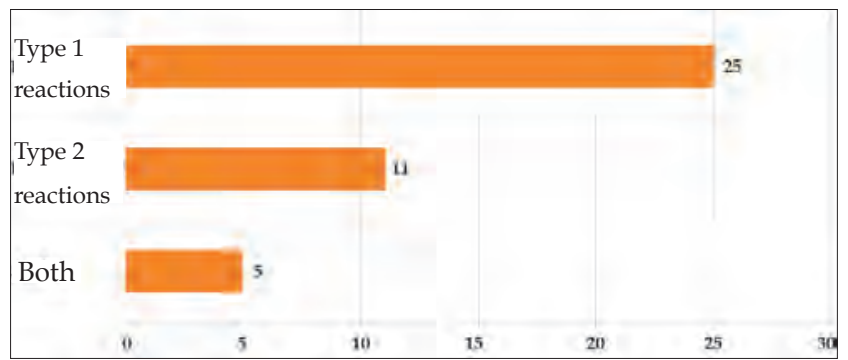

GraPH 1: Distribution of leprosy reactions from 2010 to 2015. Type 1 reactions were the most common.

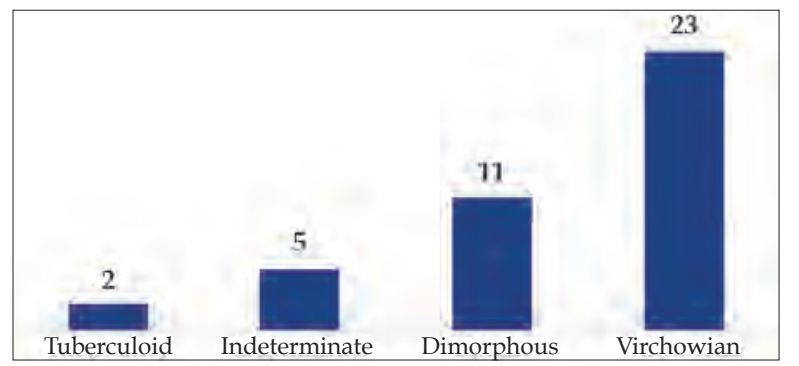

GraPH 2: Clinical forms of leprosy in patients that presented leprosy reactions. The majority of patients with leprosy reactions had the Virchowian form.

reactions, 22 cases (53.7\%) occurred in men and 19 cases $(46.3 \%)$ in women. Mean patient age was 45.77 year. Twenty-five patients (61\%) presented type 1 reactions, 11 patients (26.8\%) type 2 reactions, and five patients (12.2\%) both forms of reactions in different periods of the disease's evolution (Graph 1). The majority presented the Virchowian clinical form (23; 56.1\%) (Graph 2). As for time of onset of reactions, the majority (32 cases, $78 \%$ ) occurred during treatment of the patient's leprosy. For treatment of the patients' reactions, the drug of choice was prednisone, as monotherapy in 27 cases $(65.8 \%)$ or associated with thalidomide in eight cases $(19.5 \%)$.

\section{REFERENCES}

1. Brasil. Ministério da Saúde. Secretaria de Políticas de Saúde. Departamento de Atenção Básica. Guia para o Controle da Hanseníase. Brasilia: Ministério da Saúde; 2002.

2. Sousa AL, Fava VM, Sampaio LH, Martelli CM, Costa MB, Mira MT, et al. Genetic and immunological evidence implicates interleukin 6 as a susceptibility gene for leprosy type 2 reaction. J Infect Dis. 2012;205:1417-24.

3. Guerra JG, Penna GO, Castro LCM, Martelli CMT, Stefani MMA. Erythema Nodosum Leprosum: clinical and therapeutic up-date. An Bras Dermatol. 2002;77:389-407.

4. Becx-Bleumink M, Berhe D. Occurrence of reactions, their diagnosis and management in leprosy patients treated with multidrug therapy; Experience in the leprosy control program of the All Africa Leprosy and Rehabilitation Training Center (ALERT) in Ethiopia. Int J Lepr Other Mycobact Dis. 1992;60:173-84.

5. Cuevas J, Rodríguez-Peralto JL, Carrillo R, Contreras F. Contreras Erythema nodosum leprosum: reactional leprosy. Semin Cutan Med Surg. 2007;26:126-30.

Letícia Ambrosano

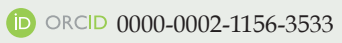

Marcel Alex Soares dos Santos
Diagnosis and management of leprosy reactions are still challenging for the dermatologist, since failure to treat reactions early can leave sequelae.

As for patients' gender, in our sample men were affected more frequently than women. The most heavily affected age bracket was the economically active population, consistent with studies in Brazil, with a heavy psychosocial impact due to the higher work activity in this group (Graph 1). ${ }^{7,9}$

Although there were more patients with Virchowian leprosy, type 1 reactions were more prevalent during the study period, which was unexpected, since Virchowian patients are more prone to evolving with type 2 reactions (Graph 2). According to Kahawita, Stephen \& Lockwood, some risk factors for type 1 reactions that are present in our patients are: positive bacillary index, age at diagnosis 15 years or older, sensory or motor loss, and more than five lesions. ${ }^{10}$

Prednisone was the most common treatment, which is not a comforting finding: although type 1 reactions are systemically less severe, they are often accompanied by neuritis, which is responsible for important damage and sequelae.

The fact that leprosy reactions were common during treatment (versus before or after) suggests a major influence from the individual's own immune behavior and reinforces the theory that treatment itself can trigger reactions. ${ }^{2-5,8}$ In multibacillary cases, like Virchowian patients, who predominated in our study, the slow elimination of dead bacilli and thus the continuous presence of their antigens increased the risk of leprosy reactions. ${ }^{2-5,8}$

Considering that nearly half of the patients presented reactions, we conclude that it is extremely important to identify and manage such cases early, since they can lead to sequelae that interfere in the patient's quality of life and even lead to disability.

The clinical characterization of reactional patients contributes positively to such identification and management, highlighting the importance of the findings presented here, since studies on leprosy reactions are rare in Brazil. Our results are similar to those of other studies reported in the literature, showing a similar profile of leprosy reactions in different states of Brazil. $\square$

6. Suchonwanit P, Triamchaisri S, Wittayakornrerk S, Rattanakaemakorn P. Leprosy Reaction in Thai Population: A 20-Year Retrospective Study. Dermatol Res Pract..2015;2015:1-5.

7. Teixeira MAG, Silveira VM, França ER. Características epidemiológicas e clínicas das reações hansênicas em indivíduos paucibacilares e multibacilares, atendidos em dois centros de referência para hanseníase, na cidade de Recife, Estado de Pernambuco. Rev Soc Bras Med Trop. 2010;43:287-92.

8. Lockwood DN, Suneetha S. Leprosy: too complex a disease for a simple elimination paradigma. Bull World Health Organ. 2005;83:230-5.

9. Kerr-Pontes LR, Barreto ML, Evangelista CM, Rodrigues LC, Heukelbach J Feldmeier H. Socioeconomic, environmental, and behavioural risk factors for leprosy in North-east Brazil: results of a case-control study. Int J Epidemiol. 2006;35:994-1000.

10. Kahawita IP, Walker SL, Lockwood DNJ. Leprosy type 1 reactions and erythema nodosum leprosum. An Bras Dermatol. 2008;83:75-82.

Elaine Cristina Faria Abrahão Machado
$\begin{array}{ll}\text { Elisangela Samartin Pegas } & \text { (D) ORCID 0000-0003-1389-5977 0000-0002-9362-9814 }\end{array}$

How to cite this article: Ambrosano L, Santos MAS, Machado ECFA, Pegas ES. Epidemiological profile of leprosy reactions in a referral center in Campinas (SP), Brazil, 2010-2015. An Bras Dermatol. 2018;93(3):460-1 